Received Date : 10-Jun-2016

Revised Date : 17-Jun-2016

Accepted Date : 28-Jul-2016

Article type : Original Article

\title{
THE IMPACT OF SINGLE AND SHARED ROOMS ON FAMILY CENTRED CARE IN CHILDREN'S
}

\section{HOSPITALS}

Penny Curtis (Corresponding author) PhD, MA, BA, RN, RM

Professor of Child and Family Health and Wellbeing

School of Nursing and Midwifery

University of Sheffield

387 Glossop Road

Sheffield

S10 2HQ

p.a.curtis@sheffield.ac.uk

0044(0)1142222040

Andy Northcott PhD, MA, BA(hons)

Research Associate

School of Healthcare Sciences

Cardiff University

Eastgate House

35-43 Newport Road

Cardiff

CF24 OAB

northcotta1@ cardiff.ac.uk

0044(0)29 20687689

\section{Acknowledgements}

The authors wish to acknowledge the contributions of Emeritus Professor Allison James to the study design and the early phases of the research, and Dr Gayle Newberry to the data collection.

This study was funded as part of Health Education Yorkshire and the Humber LETB Dignity and Respect Initiative. Additional support was provided by Sheffield Children's Hospital NHS Foundation Trust.

This article has been accepted for publication and undergone full peer review but has not been through the copyediting, typesetting, pagination and proofreading process, which may lead to differences between this version and the Version of Record. Please cite this article as doi: $10.1111 /$ jocn. 13485

This article is protected by copyright. All rights reserved. 


\section{Contributions}

Study design; PC and AJ. Data collection; GN. Data analysis; PC and AN. Manuscript preparation; PC and AN.

\section{Conflict of Interest}

The authors declare that they have no conflict of interest.

\section{THE IMPACT OF SINGLE AND SHARED ROOMS ON FAMILY CENTRED CARE IN CHILDREN'S HOSPITALS}

\section{ABSTRACT}

Aim: To explore whether and how spatial aspects of children's hospital wards (single and shared rooms) impact upon family centred care.

Background: Family centred care has been widely adopted in paediatric hospitals internationally. Recent hospital building programmes in many countries have prioritised the provision of single rooms over shared rooms. Limited attention has, however, been paid to the potential impact of spatial aspects of paediatric wards on family centred care.

Design: Qualitative, ethnographic.

Methods: Phase 1; observation within 4 wards of a specialist children's hospital. Phase 2; interviews with 17 children aged 5-16 years and 60 parents/carers. Sixty nursing and support staff also took part in interviews and focus group discussions. All data were subjected to thematic analysis.

Results: Two themes emerged from the data analysis: 'role expectations' and 'family-nurse interactions'. The latter theme comprised 3 sub-themes: 'family support needs', 'monitoring children's wellbeing' and 'survey-assess-interact within spatial contexts'.

Conclusion: Spatial configurations within hospital wards significantly impacted upon the relationships and interactions between children, parents and nurses, which played out differently in single and shared rooms. Increasing the provision of single rooms within wards is therefore likely to directly affect how family centred care manifests in practice.

This article is protected by copyright. All rights reserved. 
Relevance to clinical practice: Nurses need to be sensitive to the impact of spatial characteristics, and particularly of single and shared rooms, on families' experiences of children's hospital wards. Nurses' contribution to and experience of family centred care can be expected to change significantly when spatial characteristics of wards change and, as is currently the vogue, hospitals maximise the provision of single rather than shared rooms.

\section{KEYWORDS}

Family centred care, Single rooms, Shared rooms, Spatial characteristics, Children's hospitals, Paediatric hospitals, Children's experiences, Parents' experiences, Nurses' experiences, Ethnography

\section{What does this paper contribute to the wider global clinical community?}

- provides insights into how nurses' parents' and children's views and experience intersect to constitute family centred care in paediatric wards

- $\quad$ highlights the impact that spatial characteristics of wards, particularly single and shared rooms, have on family centred care

\section{INTRODUCTION}

Since the late 1980s, the concept of family centred care (FCC) has assumed increasing visibility in hospital care for children and is now considered to be ubiquitous: 'bandied around in most healthcare facilities across the world' (Brykczynska \& Simons 2011, p. 147). However, there are differing views about what this should and does entail, what its core attributes are and how it should manifest. A frequently cited definition alludes to "beneficial partnerships among healthcare patients, families, and providers" (IFCC n.d. p.1), which are founded upon the principles of dignity and respect, information sharing, participation and collaboration, yet this gives little insight into how FCC works in practice (Shields 2011).

While at the heart of FCC is the widely held assumption that parents want to be actively involved in their hospitalized child's care it appears that this is not always easily achieved. Previous research into

This article is protected by copyright. All rights reserved. 
FCC has illustrated and explored the tensions around sharing care delivery and the burden and opportunities that FCC affords for parents and nurses (for example Callery \& Smith 1991, Darbyshire 1994a). Inconsistencies between the expectations of care providers and parents have been reported (Shields et al. 2008) as has reticence, on the part of nurses, to share decision-making and cede control to family members (Shields et al. 2006). Family members, in turn, have pointed to the lack of support received from nurses (Corlett \& Twycross 2006, Shields et al. 2006). However, this body of research has tended to focus largely upon the perspectives and experiences of parents and nursing staff. Children's voices have been largely ignored or excluded (Lambert 2009), although there are some exceptions (Coyne \& Kirwan 2012), and there remains a need to better understand how nurses', parents' and children's views and experiences intersect to constitute FCC in practice and how such intersections may be influenced by spatial aspects of the built environment (Harrison 2010).

Spatial aspects are particularly pertinent given the trend, over recent years, for an increase in the number of single rooms, sometimes referred to as single-family or private rooms, and concomitant decrease in semi-private, or shared rooms (or bays) within paediatric hospitals internationally'. This change, initiated within the United States (US), has been justified in relation to claims for improved ambient qualities (including better light, reductions in environmental noise), enhanced infection control and assumed consumer preference (Kotzer et al. 2011, Stevens et al. 2012, Verderber \& Todd 2012, Maguire et al. 2013). However, as Verderber \& Todd (2012) point out, the prioritisation of single rooms in the US has been associated, predominantly, with private healthcare where singlefamily rooms are seen as a mark of progressiveness and a marketable asset to potential users. Verderber \& Todd (2012, p. 21) also insert a note of caution arguing that: "it is ironic that the allprivate-room template is currently being exported (prematurely) internationally without adequate research to determine its true effectiveness within the United States".

This article is protected by copyright. All rights reserved. 


\section{BACKGROUND}

In the academic literature there has, nevertheless, been a growing interest in understanding the impact of environmental design on patients' outcomes and experiences of care. A substantial body of work has sought to identify changes in users' perspectives and experiences before and after the move to reconfigured clinical areas or new hospital builds in which single rooms predominate. Not surprisingly, the bulk of this literature derives from studies located in the US, where such building programmes have proliferated (for example, Kotzer et al. 2011, Maguire et al. 2013). Such studies are predominantly quantitative in approach, utilising survey methods to generate data from health professionals and parents and to report on a broad range of issues associated with multi-component change in hospital environments including: ambient light; temperature; aesthetics; patient safety; ease of patient monitoring; parental satisfaction with care; staff mental and physical fatigue; staff walking burden and; staff stress (France et al. 2009, Kotzer et al. 2011, Yi \& Seo 2012). While children's perspectives are absent from this literature, children's room preferences have, nonetheless, been the focus of a small number of qualitative studies. Bishop (2008), for example reported that Australian children's preferences were divided equally between single and shared rooms while in a UK study a small majority of adolescents preferred shared rooms (Morgan 2010). In New Zealand (Miller et al. 1998), adolescents suggested that shared rooms had positive advantages over single rooms. Benefits of single rooms include enhanced privacy and improved facilities, such as en-suites (particularly for older children and parents), lower ambient noise, better quality of sleep, and the ability to control the local environment. However, single rooms have also been associated with disadvantages including social isolation, loneliness and boredom while shared rooms, in contrast, provide enhanced sociability and distraction ( Birch et al. 2007, Morgan 2010, Austin et al. 2013, Lambert et al. 2014).

This article is protected by copyright. All rights reserved. 
To date, therefore, the extant literature offers some insights into the environmental conditions within which children and family members experience hospital care. However, there has been little attention paid to understanding how FCC manifests on a day to day basis within different spaces or how these manifestations are experienced by children, parental adults and nurses in children's hospital wards.

\section{Space and spatiality}

Over recent years, there has been a widely acknowledged 'spatial turn' in academia, as diverse disciplines have come to regard space as an additional 'important dimension to their own areas of inquiry' (Warf \& Arias 2009, p. 1) and of relevance to understanding social and cultural phenomena. The 'spatial turn' refers to the "reworking of the very notion and significance of spatiality to offer a perspective in which space is every bit as important as time in the unfolding of human affairs", for it is not just that "everything happens in space, but because where things happen is critical to knowing how and why they happen." (ibid: Italics in original). The spatial turn is grounded in an understanding of space as socially produced, for the social and spatial are inevitably realised one in another (Keith \& Pile 1993). The influential work of Lefebvre (1991) posits three spatial elements: space as produced, conceived and lived. Abstract and material dimensions work to produce space which is constituted on an ongoing basis, according to Hackett (2015), through what people do in spaces and their enactment of daily routines. Conceived space, by contrast, refers to representational constructions of space such as those that are created through the workings of architects and planners: "A conceived space is a place for the practices of social and political power; in essence, it is these spaces that are designed to manipulate those who exist within them"

(Lefebvre 1991, p. 222). Finally, the notion of lived space captures the coming together of produced and conceived space within actors' experiences - the coming together of "how space is described and used and the symbolic meaning attached to it" (Hackett 2015, p. 86).

This article is protected by copyright. All rights reserved. 
It is this attachment of symbolic meaning that is at the heart of the (highly contested) distinction between abstract notions of space and localised associations with place. Place is where basic social practices are lived out (Merrifield 1993); in the words of Kraftl (2013) place 'matters' and is imbued with personal meaning through lived experiences; through the physical, the embodied and the emotional as well as the relational (Pink 2009, Seymour et al. 2015).

In this paper we therefore draw upon notions of spatiality as a useful heuristic lens with which to interrogate experiences of FCC within the paediatric hospital context, paying particular attention to single and shared room spaces within children's hospital wards.

\section{METHODS}

The main aim of the study from which findings derive was to explore the experiences and perceptions of hospitalised children, their parents and health professionals with respect to children's everyday care and activities of daily living. The study focused on one specialist paediatric hospital in the north of England, 2 years prior to relocation into a new build hospital extension. A focused ethnographic study (Morse 1987) was carried out in two phases over a 10 month period to understand how formal and informal care interactions took place in both single and shared rooms.

\section{Phase one}

Participant observation was carried out over a 2 month period in 4 wards, 2 surgical wards and 2 general medical wards, representing the clinical areas to be relocated into the new build. Observation focused upon activities of daily living and routine everyday care tasks including feeding, recreation, sleeping etc. in order to capture the negotiation and any variation in care routines in ward spaces.

This article is protected by copyright. All rights reserved. 


\section{Phase two}

Following completion of phase 1 , interviews and focus group discussion were carried out with family members and nursing staff.

\section{Sampling and recruitment}

Participants were recruited opportunistically from each of the 4 wards. The hospital's admission profile identified that approximately 50\% of in-patient children were aged under 5: $10 \%$ were recorded as belonging to minority ethnic groups. To ensure sufficient diversity of experience we sought to recruit 60 families for the second phase of the study: 30 families with a resident child aged under 5 and a further 30 with a child aged between 5 and 16 years of age. Sampling also embraced a wide range of hospital experiences (with respect to acuity; first time and repeat admissions; length of stay).

Fifty six families were recruited: 24 families with a resident child under 5 and 30 families with a resident child aged 5 or over. Seventeen children and young people, aged 5-16 years participated actively in the interviews ( 9 boys and 8 girls) alongside their parent/s. All but 2 of the family interviews included mothers or female guardians, while fathers participated in 8 interviews. In addition, 7 focus group discussions took place, comprising a total of 60 nurses and members of support staff from the wards observed during phase one. A further 7 individual interviews were carried out with nurses at sister/charge nurse level from the same wards and 6 were conducted with senior nurses (ward managers and above).

This article is protected by copyright. All rights reserved. 


\section{Data collection}

Semi-structured interviews with children and parents explored their perceptions, expectations and experiences of care. A range of participatory methods were utilised to enable children and parents to reflect upon their current experiences and to engage in a dialogue about how family care might be influenced by the spatial characteristics of the new build. Methods included:

- $\quad$ Playmobil $^{\circledR}$ characters $^{\mathrm{ii}}$ : used by young children to model interactions with spaces and other actors and/or to express issues of interest, concern etc.

- $\quad$ pictures of the current bed spaces and architects' designs for the new single rooms; enabling parents and children to reflect on the affordances for care offered by the physical environment.

- a 3-D 'mock-up' of the new single person cubicles as well as a large scale plan of the new hospital ward layout; enabling family members to interact with the spatial characteristics in order to contextualise discussion of the factors that might enable or constrain the negotiation of care in the new build.

The 3-D cubicle-mock-up and the new build ward plan were also used, where appropriate, during individual interviews with senior nurses and focus group discussions, when participants were invited to reflect upon current care issues and to consider the implications of the new build.

All interviews were carried out within the hospital, at times convenient to the participants. All interviews and focus group discussions were audio recorded and transcribed verbatim and anonymisation took place at the point of transcription. Pseudonyms for family members have been utilised throughout the findings section of this paper.

This article is protected by copyright. All rights reserved. 


\section{Analysis}

Wilson \& Chaddha, (2010, p. 562-3) note that:

"good ethnography is theory driven. Given the nature of ethnographic research, it is likely to be much more reflective of inductive theoretical insights than those that are purely deductive.

Moreover, in some ethnographic studies the theoretical insights are neither strictly deductive nor inductive, but represent a combination of both. We might venture to say that the most creative ethnography reflects this synthesis".

This is congruent with a thematic approach to analysis as described by Vaismoradi et al (2013, p. 399) who note that thematic analysis includes both "description and interpretation, both inductive and deductive, emphasizing context [and] integration of manifest and latent contents". In this study, thematic analysis of all data was undertaken beginning with the reading and re-reading of all transcripts and field notes generated during phase one, in order to develop a sense of the whole dataset (Polit \& Beck 2003). Following this preliminary reading, a set of initial codes was identified, from which tentative themes were developed and reviewed through a creative process of inductive and deductive reasoning as we sought to examine spatial aspects of the hospital environment. As Vaismoradi et al. (2013) note, the final stage in any thematic analysis is accomplished through the process of writing itself, when meanings are expressed within the particular context of the research. Throughout the analytical process NVivo10, a computer-based data analysis package, was used to facilitate data management.

\section{Ethical considerations}

Careful attention was given to ethical requirements that research with children and young people necessitates (Morrow \& Richards 1996, Alderson \& Morrow 2004) with respect to: negotiating access; gaining and maintaining informed consent with children and young people themselves; and ensuring anonymity. The research was conducted in compliance with the University (removed for

This article is protected by copyright. All rights reserved. 
anonymisation) ethics policy and guidance document on Ethical Considerations in Research with Children and Young People ${ }^{\mathrm{iii}}$ and the British Paediatric Association's Guidelines for the Ethical Conduct of Work Involving Children (McIntosh et al. 2000). The study received National Research Ethics Service approval.

Written consent for observation was obtained from those children old enough to provide this as well as from family members and nurses. In addition, written consent was also obtained before each interview or focus group. Participants were provided with age appropriate information sheets and invited to ask questions about the study before giving consent. Where possible, families were given information 24 hours prior to seeking consent, although this was not practical for short-stay children. In such circumstances, as this was judged to be a low risk research context, a minimum of one hour was allowed between the giving of information and the seeking of written consent.

Parents were asked to give the researcher consent to approach their child, and separate consent from children was also obtained. To enable the active participation of young children who were unable to give written consent, ongoing assent was sought. This required the researcher to remain vigilant to the child's responses at all times, to be sensitive to their communicative practices, displays of emotion and lines of interest. When a young child was considered to be disinterested, bored or distressed, then assent was deemed to be no longer current and data collection was suspended or stopped. Where young people were not accompanied by a parent/guardian, prior parental consent was not considered essential if the young person was assessed, by the researcher in liaison with the ward staff, to be competent to consent independently (Hunter \& Pierscionek 2007). The standard information and consent process was then followed.

This article is protected by copyright. All rights reserved. 


\section{FINDINGS}

Family centred care can be conceptualised as a set of fluid practices accomplished over time and within space, which manifest at the intersections between children's self-care, parental- and nursing-care. We therefore, firstly, consider how expectations about children's, parents' and nurses' roles manifest within the built environment of the hospital and then, secondly, consider how their interactions play out within different spatial configurations.

\section{Role expectations}

As we have noted, the widely held perception that parents want to be actively involved in their child's care while in hospital lies at the heart of FCC and this was the foundation upon which understandings of the child's, parents' and nurses' contributions to care were constructed. Although children may be less able to participate actively in their own care while they are unwell, other factors were also at play within the hospital environment: while parents were assumed to be active providers of care, children were, by contrast, constructed as vulnerable and dependent, reliant upon the care and the support of adults. As one senior nurse noted:

I think children's nursing's an odd area in comparison to the rest of nursing because it is family centred care as opposed to holistic care. ... (In) family centred care, the decision is made for a person, the child, and also children are dependent on somebody else for their needs, an adult isn't, by and large. (Care is being offered) by a third party really. In children's nursing they train you very much to take the whole family in from the start, but the child can't make the decision for themselves and their normal everyday life is that their needs are dependent on somebody else and you become quite dependent staff wise on somebody else filling those needs quite a lot. (Senior nurse 4).

This article is protected by copyright. All rights reserved. 
And the 'somebody else' was consistently the child's parent/s. Even when not specifically designed to facilitate co-residence of a parent, contemporary hospital spaces are commonly re-configured to enable parental stay through the provision of fold up beds or recliner chairs that are placed in close proximity to the child's bed. These spatial and material properties of the ward enabled parents to participate in their child's care around the clock while simultaneously normalising and reinforcing the expectation that parents would do so. Parents, nurses asserted in this study, would be caring for their child at home and should therefore continue to exercise that responsibility within the hospital. This has been referred to by Darbyshire (1994) as the as-if-at-home analogy:

if they were at home they would be caring for that child, doing everything for them so if they can do it in hospital then I think they should have full involvement in it (FG4).

...there is probably an expectation that if they would be helping their child dress and wash and feed at home that we would expect them to... ...I'm not saying we're right to expect that but I think probably there is, yeah, there is an expectation (Senior nurse 1).

And this analogy was also drawn upon by parents:

We wouldn't have someone else come and change his nappy at home or give him his tea at home, so why would we expect it here? (Rachel, mother of 1 year old).

In this study, the majority of parents were very willing to provide the sort of care expected of them and, indeed, were keen to do more, rather than less, for their child.

we just took it on board that they'd [nurses] do the medical side and we'd [parents] do more of the [physical] caring side for [child]. It just seemed to slip into place to be honest, we didn't really need to make a big thing of it. (Lena, mother of 9 year old).

Many of the children who were interviewed also reflected the normative assumption that parents should - and would - provide basic care while they were in hospital:

This article is protected by copyright. All rights reserved. 
Olive: (talking about her mother) She helps... She helps me on a night before I go to bed. Sometimes I get a little bit stiff because of my arthritis. If I ain't been moving that much, I get a bit stiff. Sometimes my neck goes really stiff and I can't move it, so sometimes I'm just like this...like this, just looking, and if I can't, like, look, my mum will, like, help me see what I'm doing by telling me what's what and what I'm doing. And she just helps me by caring for me and looking after me. But I think that's what mums are meant to do.

Maggie: It is, isn't it? (Maggie, mother: 11 year old Olive)

Interviewer: And if you did start to need more help, like if you did have an operation, who do you think you'd want that extra help to come from? Would you be happy for nurses to help you with everything or would there be some things you'd prefer to come from your mum?

Gabriel: I think there'd be some things that I'd prefer to come from you, but most of the stuff I'd be happy for nurses to help me with.

Interviewer: What sort of things might it be that you'd prefer your mum to help with? Gabriel: Just like changing if I need to. Washing. Pamela: Yeah washing, bath time, that sort of thing you know. (Pamela, mother: 14 year old Gabriel) The configuration of space within hospital wards and the organisation of resources within spaces, including the availability and positioning of beds or reclining chairs for parents, materialise and reproduce particular expectations around the role of the parent, child and nurse. Spatial considerations are therefore integral to FCC and to the continuing viability of contemporary service provision for hospitalised children, for as this nurse commented, "we couldn't do a job if the parents didn't stay ... If we didn't have parents resident, we'd need double our nurses. And more." (FG5:2).

This article is protected by copyright. All rights reserved. 


\section{Family-nurse interactions}

Spatial aspects of hospital wards also influenced the nature and experience of interactions between children and parents and between family members and nurses; these played out differently within different ward spaces. We therefore turn now to consider the impact of spatial characteristics on families' support needs and their perceptions of nurses' monitoring of children's well-being before, finally, considering how spatial characteristics influenced families' access to nursing support.

Families' support needs

It is, of course, essential to recognise that in wards with both shared rooms and single rooms, the latter are often allocated on the basis of clinical need. Single rooms therefore often accommodate the children who are more acutely ill or at heightened risk of infection and this, inevitably, has significance for the nursing resource that is required (Morris et al. 2014). Nevertheless, other spatial - factors also influenced child-parent and family-nurse interactions and experiences in single and shared rooms.

Shared rooms could afford both parents and children access to non-nursing sources of information, support, distraction, recreation and entertainment, and monitoring. As one nurse noted, parents in shared rooms 'look out' for one another:

Parents do look out for each other's -, you know, look out for each other and their children, not that they get involved in the care but they might say, you know, let the nurse know if they -, it's sort of, they do become like family members to each other, you know, because they spend a lot of time with each other. (Senior nurse 2)

Parents could 'keep an eye' on a child from another family to allow an adult to shower or leave the ward to buy food. Parents could also enable others to avoid the need to leave their child's bedside, as Iris explains:

Iris: 'going to get a coffee, got someone sitting here for 5 minutes, can I get you one?' or vice versa, we'll try and help, because otherwise you can go a day and you've not had anything. (Iris, mother of 7 year old)

This article is protected by copyright. All rights reserved. 
Proximity to other families allowed parents to "know what they are going through and share whatever you are going through with them" (Trisha, mother of young baby). Shared rooms also provided opportunities for sociability as this mother explained:

Interviewer: Do you think it would make much difference for you being in a cubicle rather than on a bay with other families?

Tess: See that's the only difference, like, especially when you're on your own, if you're in a bay say with 4, with 3 other people, you do get talking and it does help if you're sat on your own for hours on end, like, obviously with me I have his dad comes in and all that lot and he brings his sister and stuff, but if I was completely on my own, no other parents to interact, having a little chit chat, you know, pass half an hour talking, if you were in a cubicle you could lose that but, then again, you get your privacy at the same time (Tess, mother of 4 year old)

Children in this study also illustrated the social benefits of shared rooms, which could allow them to "make new friends" (Scarlett, 8 years old), mediated, at times, by parents as Olive made clear when she talked about her 4 bedded room:

you can have a little chit-chat. Like, if my mum's been talking to them, I'll talk to them. Like, there were a girl over there with that little girl yesterday and she had blonde hair and we started talking to her about that plane that went missing and then she started asking me what I thought had happened to it and I kept talking to her, so I were quite talkative, but I were only talkative because my mum had obviously been talking to her (Olive, 11 year old)

This support and sociability was, however, largely unavailable within single rooms. As one mother commented, "You know, it's like being in Outer Mongolia" (Jade, mother of 8 year old). Children could also experience single rooms as "a bit boring" (Isabella, 9 year old). Ten year old Beth noted that in her single room, she would have liked more opportunities to "Play with other people". It is perhaps not surprising, therefore, that nurses reported that they found it difficult, at times, to withdraw from single rooms, feeling that they could get "stuck in there" (FG1): "If you've got a family of a child in a cubicle and you're their nurse, they forget that you also have other patients" (FG3). Nurses therefore

This article is protected by copyright. All rights reserved. 
perceived the spatial characteristics of single rooms to generate additional family support needs, which they struggled to meet within an already stretched nursing resource.

Monitoring children's wellbeing

As well as the lack of sociability and informal support afforded to families in shared rooms, parents and children also highlighted a further spatial characteristic that impacted on the nature and experience of care in single rooms. In shared rooms, parents derived considerable reassurance from the visible presence of nurses and what was recognised by both parents and nurses as ongoing, informal monitoring of children's well-being. Nurses repeatedly referred to the significance of such informal observation; to having "eyes in your bottom", noting that "you're constantly observing aren't you? When you're not officially observing" (FG3). Spatial characteristics have a clear and direct impact on nurses' ability to 'observe when they're not observing': as one nurse noted 'in the bay, you'll see a patient probably twice as much as you would in a cubicle" (FG5). In single rooms, parents and children felt isolated from this ongoing, informal support and monitoring: "if you need anything you just have to keep going outside and for any little thing you just have to go find the nurses and stuff" (Trisha, mother of young baby). Trisha explained:

Whenever I have been in a cubicle I have found that the number of visits the nurses make to the patient go down. They only come when they have to give out some medicine or something - so that's what I found happened whenever we had to be in a cubicle. Otherwise - whereas in a bay a nurse might come to see that patient and then suddenly that baby goes a bit - you know starts choking or something, she would then do that baby and then go and help - so that's been because I think being in a bay.

Similarly:

I think because he's in a cubicle as well, it's different isn't it, you don't get the passing -, I suppose if you're on the open part of the ward, you might get a bit more of that but I don't think it's bothered you, I think he's quite liked it, but he gets, sort of, like less of that, don't you, I suppose, the passing.

(Elaine, mother of 15 year old)

This article is protected by copyright. All rights reserved. 
Although Elaine felt that her son had not been 'bothered' by the lower level of informal monitoring, children did nevertheless voice their awareness of this:

there is no nurses just like walking past, so you can't really like, if you need something you can't just shout them. You've got to like, as they're walking past, or they're not going to walk past and then like ask if you are okay, so, and if like my drip's beeping I've got to press my button. They're not just going to notice it. (Gabriel, 14 year old).

For some parents, this less frequent, informal monitoring in single rooms induced a reluctance to leave their child; Jade, the mother who likened their single room to Outer Mongolia, explained this reluctance:

Yes. I hate being shoved up in a cubicle. As I say, there's a sort of nervousness of going to get a coffee or going downstairs to fetch sandwiches or something, 'cause if he's poorly, although I can say to the nurse, 'I'm leaving him', I know he's not under her eyes at that point. You know, which is for me scary 'cause he can't shout out. He can't tell anybody what's going on. So he will just silently do something... So I like him where we can see him, on full view, where everybody can see what he's up to. (Jade, mother of 8 year old)

This reluctance - and its rationale - was also recognised by nurses:

Senior nurse 4: I think, to some extent, some families probably feel like they need to stay in the cubicle because people aren't walking past as often and you can't -, in the open bays are lots of other people around and they probably feel more confident that there's somebody there, whereas you're a little bit more isolated in a cubicle and it depends very much when the nurses are coming in and doing the observations or the drugs or bringing the tea in or Interviewer: So just seeing you going up and down you feel is kind of reassuring to Senior nurse 4: I think for certain families it is, yeah.

The spatial characteristics of single rooms, therefore, gave rise to enhanced family support needs that were associated with family member's inability to draw upon non-nursing resources and with the

This article is protected by copyright. All rights reserved. 
widely remarked upon reduction in opportunities for informal monitoring, by nurses, of children's health and wellbeing.

\section{Survey-assess-interact within spatial contexts}

Families were very aware of and sensitive to nurses' heavy workloads. As Pippa, the mother of a young baby noted, 'I reckon the nurses have got enough to be doing rather than helping me bath him, you know. He's fine without a bath'. Children also recognised nurses' 'busyness'. Gabriel (14 year old), for example, commented that he did sometimes feel guilty just chatting to the nurses because he recognised how busy they were and this sentiment was reiterated by Noel (15 year old): 'When the nurses come in and do all my medicine stuff, I'll talk to them a bit, but obviously not for long periods of time because they're busy'.

In such circumstances, parents and children worked hard to avoid situations where they might be seen to be interrupting nurses unnecessarily, or making undue demands upon their time.

I don't push the buzzer unless... The only time I pushed the buzzer is when you were in last time when the machines were bleeping and they've got to come and sort them and they take-sometimes if they're dealing an emergency it comes on and they know you're waiting. But otherwise, I'll either wait for - if it's not urgent, just wait for them to come back in and ask them then, or if no-one's around, go to the station and ask. We don't press the buzzer. (Kate, mother of 8 year old) Interviewer: If you need any help with anything and you wanted to call a nurse do you tend to sort of pop out and try and find somebody or do you use the buzzer to call them to come here? Carla: I would pop out and see if I could find somebody. We haven't needed that really except to ask for like a jug of water or something. But there's always people passing so I just nobbled somebody in the corridor. I always feel that it's sort of more for emergencies or for people who can't get up and about to use the buzzer so I sort of didn't use that. (Carla, mother of 11 year old)

This article is protected by copyright. All rights reserved. 
Parents in particular made a clear distinction between the mundane and the exceptional; unless the situation demanded urgent or emergency care, parents and children frequently initiated interaction with nursing staff by firstly, surveying ward spaces, enabling them to - secondly - assess staff 'busyness' and availability within those spaces and, finally, when an appropriate opportunity presented, initiating contact. Spatial characteristics of single rooms also impacted directly upon, and posed challenges for, family members' enactment of the survey-assess-interact strategy.

I think probably out here you can catch nurses' attentions as they're passing and things like that, which actually makes it slightly easier. Because when you're in the cubicle, if the door's closed, they have to make a positive effort to come in. (Libby, mother of 15 year old)

Sometimes, Maggie (mother of 11 year old) noted, being in a single room "is a bit difficult. Like, if you go out onto the corridor, there's sometimes no-one about to ask or anything". Families drew a clear contrast between shared and single rooms in this regard.

Spatial characteristics of single rooms that enabled greater privacy also inhibited surveillance and assessment of nurses' busyness, and impeded family members' opportunities for interaction with nurses: families "find it much harder to find - you know, just to go out of your door and find staff just, you know, in passing" (Patience, mother of 5 year old). Eleven year old Olive described how she managed this process from her single room illustrating, as she does so, her astute awareness of the survey-assess- interact strategy.

Interviewer: And do you normally have to sort of call a nurse when you want something or do they tend to just come round anyway?

Olive: They just come round. The - sometimes they're, like, there when you don't really need them, and then when you do need then, they're not there. Interviewer: Yeah.

Olive: Because they're having to deal with somebody else or having a little break. Interviewer: Yeah.

This article is protected by copyright. All rights reserved. 
Maggie: 'Cause they need a little break sometimes, I guess, 'cause the nurses are always running about.

Interviewer: And if you wanted one of them when they weren't kind of around here, how do you think you would get them? Would you ring your buzzer to fetch them, or would you sort of go out looking to find somebody?

Olive: Well, if I wanted - if I want a nurse, l'll go out - I'll stand on't corridor, and I'll just stand under that little light thing over there. And I'll stand under it and somebody 'll say, 'Are you OK?' Like a nurse - maybe like a nurse who wasn't looking after me. They'll say, 'Are you OK? Do you need help?' And I'll say, 'Yeah, please, can I have a pillow? Can I have some spare bedding for my mum?' (Maggie, mother; 11 year old Olive)

The survey-assess-interact strategy was a continuing motif in family members', and particularly parents', discussions, constituting a cultural practice that was deeply embedded in the wards in which this research took place. As this senior nurse noted: "they'll wander out and see if they find someone at the nurses' station or find someone walking along the corridor and ask them" (Senior nurse 2). Nurses also reflected similar concerns to those voiced by parents and suggested that a spatial configuration that prioritised single rooms raised significant care issues. Family members, they argued, would be more likely to "look out the cubicle and it could just be like a silent corridor because we're all in different rooms" (FG5). This concern was summed up in the following discussion:

FG2: nurse 6 Be more daunting as a parent. If you're in a cubicle and you need to go out to get a nurse if you've been in that cubicle all the time, to go out and then wander up and down a corridor and you don't know where a nurses station is or you don't know where your nurse is going to be or you see them but they're in another cubicle, what do they do? Stand outside that cubicle to wait to get your attention or like, then maybe -

FG2: nurse 2 More frustration for the parent as well.

This article is protected by copyright. All rights reserved. 
FG2: nurse 6 - they'd stay in their room or not say anything to you that they needed help until you came in or just saw you walked past and quickly try and bob out and get your attention, whereas in a bay you're more, you're seen aren't you? You're seen and they can quickly grab you andFG2: nurse 2 Yeah cos if you're doing something you go "Oh I'll just be there in a minute". You do often say that. You can see someone wants your attention.

FG2: nurse 6 Whereas you're not going to, as you walk past the room you're not going to pop in and say "I'll be there in a minute" you're just going to carry on and think right I'll go back to them in a second. They're not going to get as much interaction off you.

\section{DISCUSSION}

In this paper we have argued that spatial configurations within hospital wards significantly impact upon the day to day practice of FCC, and the experiences of hospitalised children, parental adults and nurses. James \& Curtis (2012) have suggested that "particular constructions of 'the child' and 'childhood' are threaded through public discourses and come to be realized in institutional settings" and our study has illustrated ways in which spatial configurations and materialities encode and reproduce such constructions within hospital wards. Children are positioned as largely passive, vulnerable and in need of adult support while parents are seen as active advocates for their children and contributors to their care, reflecting normative cultural expectations about family relationships and the familialisation of children's lives. Brannen \& O'Brien (1995, p. 732) have argued that when children are conceptualised in such a manner, predominantly in relation to their families, their active engagement is obscured and their dependency status over emphasised. While they also suggest that institutionalisation and familialisation are contradictory processes in children's lives, within the context of the hospital ward, the two processes co-align to influence children's - and parents' experiences of hospitalisation.

This article is protected by copyright. All rights reserved. 
Such encoding of children's and parents' role expectations and identities within hospital spaces through, for example, the facilitation of parental co-residence reflects Lefebrevre's notion of a conceived space; one that is designed to "manipulate those who exist within them" (Lefebvre 1991, p. 222). This does not imply that children and parents are coerced, against their will, to conform to particular expectations. As we have noted, in common with findings from other studies (for example, Romaniuk et al. 2014), parents both expected and wanted to provide care for their children and children, likewise, both expected and wanted their parents to do so. Rather, as Satta has noted: Children's spatiality is not [ ] simply tied to the presence/absence of adults but rather to the way in which the adults themselves perceive their adulthood based on their vision of what constitutes a 'proper adulthood', a 'proper childhood' and a proper 'adult-child relationship' (Satta 2015, p. 193)

The nature of the care that parents provide for their children and the interactions between parents and children and family members and nurses are also influenced, at a fundamental level, by spatial aspects of children's hospital wards. Our findings, that shared rooms were associated with greater sociability, and single rooms with greater privacy but also lower sociability and increased boredom, both for children and parents, accord with findings from other studies (Birch et al. 2007, Austin et al. 2013, Lambert et al. 2014). These factors give rise to concerns, from nurses, that families accommodated in single rooms are liable to make additional calls upon nurses' time in order to meet their social support needs.

However, we have also shown a further, and arguably more significant, distinction that families drew between single and shared accommodation. Parents in single rooms were concerned that their children missed out on the informal monitoring that took place on an ongoing basis within shared hospital ward spaces. The nature of the space occupied by families therefore impacted directly upon family members (Seymour 2015) and upon the parent-child relationship, as parents expressed a lack of willingness to leave their child unattended.

This article is protected by copyright. All rights reserved. 
Parents' sensitivity to what they perceive to be nurses' heavy workloads has also been reported previously in the literature (Shields et al. 2006). We have shown that children are also aware of nurses' 'busyness' and that they may modify their behaviour in light of this. In response to nurses' busyness, families were anxious to avoid being seen as over-assertive and, as Kristensson-Hallström \& Elander (1997) argued, some two decades ago, family members therefore sought ways to avoid making a 'nuisance' of themselves. Parents in this study described the use of a 'survey-assessinteract' strategy within hospital wards that minimised the likelihood that their interaction with nurses would be judged as inappropriate. Spatial issues variably enabled or constrained the ease with which this strategy could be successfully utilised. The characteristics of single rooms that contributed to enhanced privacy by restricting both visual and auditory access to family members also placed significant limits on families' visual and auditory access to other ward spaces. The potential to survey and assess prior to initiating interaction was severely limited in single rooms and parents and children described needing to move beyond the single room into shared ward spaces in order to initiate interactions with nurses. In this regard, the single room door becomes an important boundary and a threshold over which the nurses' gaze was significantly attenuated. This finding resonates with the work of Gabb (2008), who demonstrates the influence that different spaces within domestic environments have on emotional interactions. Gabb draws particular attention to boundary areas, including bedroom doors as sites of complex emotions and tensions These sites of tension are, as Seymour (2015 p. 151) argues, "spatial indications of where agency is being enacted, not always successfully".

\section{Limitations}

The findings reported in this paper derive from research undertaken in one Children's Hospital in the North of England. Although recruitment of families was not restricted to daytime, as the researcher also sought to recruit during evenings and at weekends, it is likely, nonetheless, that parents who were able to stay with their children were over-represented. Furthermore, resident parents may

This article is protected by copyright. All rights reserved. 
have had more positive views and experiences of FCC than non-resident parents. The views and experiences of non-resident parents, and the views and experiences of their children, therefore require further clarification.

In addition, despite the research team's efforts to recruit from minority ethnic communities, this did not prove to be possible. We were unable to identify access or recruit families from the 2 minority ethnic communities that had been highlighted as significant users of translation services within the study site. The voices of minority ethnic families were therefore under-represented. The findings presented in this paper should be read with these limitations in mind when considering their applicability beyond the specific study context. While generalisability is always a thorny issue as extrapolation can never, as Polit and Beck (2010, p. 1452) argue, "be fully justified because findings are always embedded within a context", nevertheless as Ayres et al. (2003) note, no matter how it is described, qualitative analysis does end in a generalization. The nature of the generalisation produced through this study accords with Mason's notion of theoretical generalisability in which the "detailed and holistic explanation of one setting, or set of processes, [can] frame relevant questions about others" (Mason 2002, p. 196).

\section{CONCLUSION}

By applying a spatial lens we have shown how lived spaces are constituted within wards, as the actions of children, parents and nurses enmesh with the conceptualisations of architects and service commissioners. Indeed, place 'matters' (Kraftl, 2013) in hospital wards. To date, however, the extensive literature exploring influences upon and manifestations of FCC has tended to disregard or underplay the significance of spatial characteristics of care environments. Our findings may therefore have significant clinical implications in light of the current prioritisation of single rooms in re-configured and new-build hospitals for children. While FCC builds, in principle, upon negotiation between children, parents and nurses, in practice it is firmly anchored in the assumption of, and 
reliance upon, parental presence and parents' active participation in children's care. This assumption is literally built into the ward environment as spatial configurations make available particular subject positions for the child, the parent and the nurse.

While privacy versus sociability has been widely discussed in relation to single and shared rooms, the affordances of different ward spaces cannot be adequately conceptualised in these terms. Undeniably, single rooms offer privacy, enhanced control over the local environment and, often, enhanced amenities. Shared rooms offer informal support networks for both children and their parents and allow passive surveillance of children's wellbeing by nurses and thus reassurance, through their overt presence, for family members. However, as we have shown, spatial configurations also impact directly upon the relationships and interactions between children, parents and nurses that are fundamental to FCC. Increasing the provision of single rooms within wards is therefore likely to directly affect how FCC manifests in practice, not least because single rooms disrupt the survey-assess-interact strategy with which families manage the delicate process of negotiating support within the busy and complex environment of the modern hospital ward. Despite the reluctance of families to utilise nurse -call 'buzzers', where single-rooms predominate, parents and children may have to assertively seek nursing support rather than passively receiving it. If modernizing the built environment of the children's ward requires a greater reliance upon single rooms, a reconceptualisaton of FCC, which pays sufficient attention to spatiality may be timely and indeed necessary to ensure that care standards are maintained and families' experiences of hospitalisation are optimised.

\section{RELEVANCE TO CLINICAL PRACTICE}

Nurses need to be sensitive to the impact of spatial characteristics, and particularly of single and shared rooms, on families' experiences of children's hospital wards. The relationships and interactions through which FCC manifests on a day to day basis play out differently in these different spaces. Nurses are uniquely positioned to recognise and respond to parental concerns about the lack

This article is protected by copyright. All rights reserved. 
of ongoing, informal monitoring of their child's wellbeing when they are accommodated in single rooms. Enabling parents and children to proactively assert their support needs also requires nurses to be sensitive to families' survey-assess-interact strategy and the particular challenges that are associated with utilising this strategy while resident in single rooms. A key message for clinical practice is therefore that nurses' contribution to and experience of FCC can be expected to change significantly when spatial characteristics of wards change and, as is currently the vogue, hospitals maximise the provision of single rather than shared rooms.

\section{REFERENCES}

Alderson P, Morrow V (2004). Ethics, social research and consulting with children and young people (2nd ed.). Barkingside: Barnado's.

Austin D, Prieto J, Rushforth $\mathrm{H}$ (2013). The child's experience of single room isolation: a literature review. Nursing Children and Young People, 25(3), 18-24. doi:http://dx.doi.org/10.7748/ncyp2013.04.25.3.18.e145

Ayres L, Kavanagh K, Knafl K (2003). Across-case, Within-case and Across-case approaches to qualitative data analysis. Qualitative Health Research, 13, 871-883. doi:doi: $10.1177 / 1049732303013006008$

Birch J, Curtis P, James A (2007). Sense and Sensibilities: In Search of the Child-Friendly Hospital. Built Environment, 33(4), 405-416. doi:http://dx.doi.org/10.2148/benv.33.4.405

Bishop K (2008). From their perspectives: Children and young people's experience of a paediatric hospital environment and its relationship to their feeling of well-being. PhD Thesis. University of Sydney. Retrieved from http://hdl.handle.net/2123/3962

Brannen J, O'Brien M (1995). Childhood and the sociological gaze. Sociology, 29(4), 729-738. doi:10.1177/0038038595029004011

Brykczynska G, Simons J (2011). Ethical and Philosophical Aspects of Nursing Children and Young People. London: Wiley Blackwell.

This article is protected by copyright. All rights reserved. 
Callery P, Smith L (1991). A study of the role negotiation between nurses and parents of hospitalised children. Journal of Advanced Nursing, 16(7), 772-781. doi:10.1111/j.1365-

2648.1991.tb01756.x/pdf

Corlett J, Twycross A (2006). Negotiation of parental roles within family-centred care: a review of the literature. Journal of Clinical Nursing, 15(10), 1308-1316. doi:10.1111/j.1365-

2702.2006.01407.x

Coyne I, Kirwan L (2012). Ascertaining children's wishes and feelings about hospital life. Journal of Child Health Care, 16(3), 293-304. doi:10.1177/1367493512443905

Darbyshire P (1994a). Parenting in Public. Parental participation and involvement in the care of their hospitalised child. In P. Benner (Ed.), Interpretive Phenomenology: Embodiment, Caring, and Ethics in Health and IIIness (pp. 185-210). London: Sage.

Darbyshire P (1994b). Parenting in public: A study of the experiences of parents who live-in with their hospitalised child, and of their relationships with paediatric nurses. London: Chapman \& Hall.

Department of Health. Health Buildings Note (HBN) 23 Hospital accommodation for children and young people (2004) Downloaded from:

https://www.gov.uk/government/uploads/system/uploads/attachment_data/file/142895/HBN _23.pdf

France D, Throop P, Joers B, Allen L, Parekh A, Rickard D, Deshpande J (2009). Adapting to familycentred hospital design: Changes in providers' attitudes over a two year period. HERD: Health Environments Research \& Design Journal, 3(1), 79-96. doi:10.1177/193758670900300107

Gabb J (2008). Researching Intimacy in Families. Basingstoke: Palgrave Macmillan.

Hackett A (2015). Children's Embodied Entanglement and Production of Space in a Museum. In A. Hackett, L. Procter, J. Seymour (Eds.), Children's Spatialities Embodiment, Emotion and Agency (1st ed., pp. 75-92). London: Palgrave Macmillan.

Harrison T (2010). Family Centered Pediatric Nursing Care: State of the Science. Journal of Paediatric Nursing, 25(5), 335-343. doi:10.1016/j.pedn.2009.01.006

This article is protected by copyright. All rights reserved. 
Hunter D, Pierscionek B (2007). Children, Gillick competency and consent for involvement in research. Journal of Medical Ethics, 33(11), :659-662. doi:10.1136/jme.2006.018853

IFCC. (n.d.). PATIENT- AND FAMILY-CENTERED CARE. Retrieved from http://www.ipfcc.org/pdf/CoreConcepts.pdf

James A, Curtis P (2012). Constructing the sick child: the cultural politics of children's hospitals. The Sociological Review, 60(4), 754-772. doi:10.1111/j.1467-954X.2012.02132.x

Keith M, Pile S (1993). Place and Politics of Identity. London: Routledge.

Kotzer A, Zacharakis S, Raynolds M, Buenning F (2011). Evaluation of the Built Environment: Staff and family satisfaction pre- and post-occupancy of The Children's Hospital. HERD: Health Environments Research \& Design Journal, 4(4), 60-78. doi:10.4037/ccn2012785

Kraftl P (2013). Geographies of Alternative Spaces of Education: Diverse Learning Spaces for Children and Young People. Bristol: Policy Press.

Kristensson-Hallström I, Elander G (1997). Parents' experience of hospitalization, different strategies for feeling secure. Pediatric Nursing, 23(4), 361-367. doi:10.1046/j.1365-2702.1999.00282.x

Lambert V (2009). Response to Carter, B (2008) Commentary on Shields L, Pratt J, Hunter J (2006) Family Centred Care: A review of qualitative studies. Journa of Clinical Nursing 15, 1317-1323 In Journal of Clinical Nursing 17, 2091-2093. Journal of Clinical Nursing, 18(4), 623-624. doi:10.1111/j.1365-2702.2008.02679.x

Lambert V, Coad J, Hicks P, Glacken M (2014). Young children's perspectives of ideal physical design features for hospital-built environments. Journal of Child Health Care, 18(1), 57-71. doi:10.1177/1367493512473852.

Lefebvre H (1991). The Production of Space. Translated by Nicholson-Smith. Oxford: Basil Blackwell. Maguire D, Burger K, O’Donnell P, Parnell L (2013). Clinician perceptions of a changing hospital environment. Health Environments Research \& Design Journal, 6(3), 69-79. doi:10.1177/193758671300600306

Mason J (2002). Qualitative Researching (2nd ed.). London: Sage.

This article is protected by copyright. All rights reserved. 
McIntosh N, Bates P, Brykczynska G (2000). Guidelines for the ethical conduct of medical research involving children. Archives of Disease in Childhood, 82, 177-182. doi:10.1136/adc.82.2.177

Merrifield A (1993). Place and space: a Lefebvrian reconciliation. Transactions of the Institute of British Geographers, 18(4), 516-531. doi:10.2307/622564.

Miller N, Friedman S, Coupey S (1998). Adolescent preferences for rooming during hospitalisation. Journal of Adolescent Health, 23(2), 89-93. doi:10.1016/S1054-139X(98)00015-9

Morgan $H$ (2010). Single and shared accommodation for young patients in hospital. Paediatric Nursing, 22(8), 20-24. doi:10.7748/paed2010.10.22.8.20.c7997

Morris K, Oppong R, Holdback N, Coast J (2014). Defining criteria and resource use for high dependency care in children: An observational economic study. Archives of Disease in Childhood, 99(7), 652-658. doi:10.1136/archdischild-2013-305133

Morrow V, Richards M (1996). The ethics of social research with children: an overview. Children \& Society, 10, 90-105. doi:10.1111/j.1099-0860.1996.tb00461.x

Pink S (2009). Doing Sensory Ethnography, London: Sage.

Polit D, Beck C (2003). Nursing Research: Principles and Methods (7th ed.). Philadelphia, PA: Lippincott Williams and Wilkins.

Polit D, Beck C (2010). Generalization in quantitative and qualitative research: Myths and strategies. International Journal of Nursing Studies, 47(11), 1451-1458. doi:10.1016/j.ijnurstu.2010.06.004 Romaniuk D, O'Mara L, Akhtar-Danesh N (2014). Are parents doing what they want to do? Congruency between parents' actual and desired participation in the care of their hospitalized child. Issues in Comprehensive Pediatric Nursing, 37(2), 103-121. doi:10.3109/01460862.2014.880532.

Satta C (2015). A Proper Place for a Proper Childhood? Children's Spatiality in a Play Centre. In A. Hackett, L. Procter, J. Seymour (Eds.), Children's Spatialities Embodiment, Emotion and Agency (pp. 178-197). Basingstoke: Palgrave Macmillan.

Seymour J (2015). Approaches to Children's Spatial Agency: Reviewing Actors, Agents and Families.

This article is protected by copyright. All rights reserved. 
In A. Hackett, L. Procter, J. Seymour (Eds.), Children's Spatialities Embodiment, Emotion and Agency (1st ed., pp. 147-162). London: Palgrave Macmillan.

Seymour J, Hackett A, Procter L (2015). Introduction: Spatial perspectives and childhood studies. In J. Seymour, A. Hackett, L. Procter (Eds.), Children's Spatialities Embodiment, Emotion and Agency (pp. 1-20). London: Palgrave Macmillan.

Shields L (2011). The ethics of family-centred care for hospitalised children. In G. Brykczynska \& J. Simons (Eds.), Ethical and philosophical aspects of nursing children and young people. London: Wiley.

Shields L, Pratt J, Hunter J (2006). Family centred care: a review of qualitative studies. Journal of Clinical Nursing, 15(10), 1317-1323.

Shields L, Young J, McCann D (2008). The needs of parents of hospitalized children in Australia. Journal of Child Health Care, 12(1), 60-75. doi:10.1177/1367493507085619.

Vaismoradi M, Turunen H, Bondas T (2013). Content analysis and thematic analysis: Implications for conducting a qualitative descriptive study. Nursing and Health Sciences, 15(3), 398-405. doi:10.1111/nhs.12048

Verderber S, Todd L (2012). Reconsidering the semiprivate inpatient room in US hospitals. HERD:

Health Environments Research \& Design Journal, 5(2), 7-23. doi:10.1177/193758671200500204

Warf B, Arias S (2009). Introduction: the reinsertion of space into the social sciences and humanities. In B. Warf \& S. Arias (Eds.), The Spatial Turn: Interdisciplinary Perspectives (pp. 1-10). London: Routledge.

Wilson W, Chaddha A (2010). The role of theory in ethnographic research. Ethnography, 10(4), 549564.

Yi L, Seo HB (2012). The effect of hospital unit layout on nurse walking behavior. HERD: Health Environments Research \& Design Journal, 6(1), 66-82. doi:10.1177/193758671200600104

This article is protected by copyright. All rights reserved. 
'For example (all URLs accessed Feb $19^{\text {th }} 2016$ ):

- UK [Department of Health 2004]

- US [Verderber \& Todd 2012]

- Australia - (http://www.lendlease.com/Australia/Projects/the-new-royal-childrenshospital.aspx - Melbourne Royal children's hospital, 2014 http://www.newchildrenshospitalproject.health.wa.gov.au/Information/patientsfamilies.asp $\underline{x}$ - Perth Children's hospital (2016)

https://www.health.qld.gov.au/childrenshealth/docs/news/lcch-brochure.pdf Lady Cilento Children's hospital, Brisbane 2014.

- Canada - Montreal Children's Hospital http://www.thechildren.com/about/our-new-hospital Children's Hospital of Saskatchewan (due to open 2019) https://childrenshospitalsask.ca/thehospital/

- Sweden - Gotheberg - announced 2015 https://childrenshospitalsask.ca/the-hospital/

ii Small, plastic posable figures (http://www.playmobil.co.uk/)

iii Removed for anonymisation

This article is protected by copyright. All rights reserved. 